\title{
INOVAÇÕES DO CÓDIGO CIVIL BRASILEIRO DE 2002 NA DISCIPLINA DO NEGÓCIO JURÍDICO SIMULADO
}

\author{
INNOVATIONS ON THE BRAZILIAN CIVIL CODE OF 2002 CONCERNING THE \\ NORMATIVE DISCIPLINE OF SIMULATED TRANSACTIONS
}

\section{Angela Cristina Viero*}

Submissão: 10/06/2013

Aceito para Publicação: 14/08/2013

Sumário: Introdução. 1. A (ir)relevância dos fins pretendidos pelas partes no negócio jurídico simulado. 1.1. Simulação lícita e simulação ilícita: noções gerais. 1.2. A disciplina do Código Civil brasileiro de 2002: causa da simulação e sanção de nulidade. 2. Efeitos da simulação. 2.1. Entre as partes. 2.2. Perante terceiros. 2.2.1. Terceiros de boa-fé. 2.2.2. Conflito entre terceiros de boa-fé. 2.2.3. A solução do Código Civil italiano de 1942 e as "recomendações" doutrinárias na Argentina. Considerações finais. Referências.

Resumo: O presente artigo tem por objetivo analisar a disciplina do Código Civil de 2002 no que se refere à simulação nos negócios jurídicos. O Código Civil atualmente em vigor inovou na regulamentação dos negócios jurídicos simulados em relação ao Código Civil revogado, fundamentalmente quanto à causa da simulação para que o fenômeno seja relevante para o Direito, bem como no que concerne à dimensão no mundo dos fatos jurídicos em que se situa o negócio jurídico simulado, com implicações nos efeitos da simulação entre aqueles que dele participam (partes) e aqueles que lhe são alheios (terceiros). Da sanção de nulidade prevista no art. 167, caput, decorre a possibilidade de arguição da simulação entre as partes entre si, circunstância que deve ser analisada com cautela em cada caso concreto, a fim de evitar que o escopo da simulação, quando fraudulenta, seja concretizado. Por outro lado, prevê o Código Civil de 2002 a inoponibilidade da simulação pelas partes em face dos terceiros de boa-fé, em homenagem à tutela da confiança com a finalidade de preservação da segurança jurídica. Não obstante, quanto a este último aspecto, não há previsão de critérios que auxiliem na solução de eventuais conflitos entre diferentes categorias de terceiros de boa-fé.

Palavras-chave: Negócio Jurídico Simulado; Código Civil brasileiro de 2002; Causa da simulação; Nulidade; Efeitos.

\footnotetext{
${ }^{*}$ Universidade Federal do Rio Grande do Sul.
} 


\section{Volume VIII | Número 1 | Ano 2013}

Abstract: This article aims to analyze the normative discipline of the simulated transactions on the Brazilian Civil Code of 2002. The Civil Code currently in force has innovated on the rules about simulated transactions in comparison to the revoked Civil Code, fundamentally in relation at the motive of the simulation to become relevant for the legal system, as well as concerning the dimension on the world of facts in which are situated the simulated transactions, involving the effects of the simulation among the participants on it (parties) and those who are out of it (third parties). From the nullity sanction settled by the art. 167, caput, arises the possibility to argue for the simulation of the parties among themselves, circumstance that must be analyzed prudently in each case, to avoid that the objective pursued with the simulation, when it is fraudulent, to be rendered concrete. By the other hand, the Civil Code of 2002 settles to the parties the impossibility of opposing the simulation against thirds parties in good faith, in honor to protect trust intending to preserve legal certainty. Nevertheless, as far as this last aspect is concerned, there are not forecasted criteria to support solutions for eventual conflicts between different categories of thirds parties in good faith.

Keywords: Simulated transactions; Brazilian Civil Code of 2002; Motive of simulation; Nullity; Effects.

\section{INTRODUÇÃO}

A simulação constitui instigante e complexo fenômeno jurídico, que, de há muito, suscita controvérsias doutrinárias referentes à sua elaboração dogmática e à sua regulamentação.

No Brasil, com o advento do Código Civil de 2002, a disciplina aplicável aos negócios jurídicos simulados sofreu relevantes alterações em relação ao Código Civil de 1916: no que concerne à licitude ou ilicitude da simulação para que seja considerada fato relevante para o Direito; no atinente à dimensão no mundo dos fatos jurídicos em que se situa o negócio jurídico simulado e, consequentemente, aos efeitos da simulação entre aqueles que dele participam e aqueles que lhe são alheios (terceiros).

Em outros termos, as regras pertinentes à simulação, introduzidas pelo Código Civil de 2002, apresentam, basicamente, duas inovações: no tocante à irrelevância dos fins pretendidos pelas partes como fator determinante de aplicação das normas relativas ao tema; no que diz respeito aos efeitos do negócio jurídico simulado, inter partes, e em relação a terceiros.

Estes aspectos, bem como a análise crítica das consequências deles decorrentes, constituem, respectivamente, a primeira e a segunda parte do presente artigo. 


\section{A (IR)RELEVÂNCIA DOS FINS PRETENDIDOS PELAS PARTES NO NEGÓCIO JURÍDICO SIMULADO}

\subsection{Simulação lícita e simulação ilícita: noções gerais}

Entende-se por causa simulandi o interesse que leva as partes a celebrar um negócio jurídico simulado. Trata-se do motivo que induz a dar aparência a um negócio que não existe, o porquê do engano, e, segundo a doutrina de Jorge Mosset Iturraspe ${ }^{1}$ :

Como en el orden del accionar humano y, más aún, en el mundo de los negocios jurídicos no es verosímil un actuar sin causa, sin motivo determinante, es decir la comisión de un acto que no responda a una finalidad predeterminada, puede concluirse afirmando que el engaño, que es de la esencia de toda simulación, obedece siempre a una causa.

Segundo o critério das causas ou dos motivos que movem as partes na realização de um negócio jurídico simulado, a simulação pode ser classificada como lícita ou ilícita.

A simulação lícita ou inocente é aquela que não tem por objetivo prejudicar terceiros ou fraudar a lei, ou que, objetivamente, não lese terceiros nem viole disposição legal. O motivo determinante se vincula a um interesse justificado; há engano, mas não prejuízo.

A doutrina cita como exemplos de simulação lícita: alguém que pretende enganar um

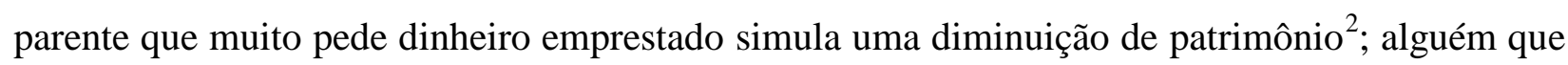
quer enganar terceiros, por mera ostentação, dando a impressão de riqueza, simula a compra de um imóvel valioso; um pai que possui um vultoso patrimônio, com a finalidade de estimular seu filho ao trabalho ou ao estudo, finge a perda de grande parte dos seus bens, transferindo-os, simuladamente, a terceiros ${ }^{3}$.

A mais frequente, no entanto, é a simulação ilícita, nocente ou fraudulenta, aquela que tem por objetivo lesar direitos de terceiros ou burlar a lei.

São exemplos de simulação ilícita: os negócios jurídicos de alienação de bens realizados pelo devedor quando visem a aparentar, em face dos credores, diminuição do ativo; a compra e venda de bem imóvel por valor inferior ao real para que o imposto incidente seja reduzido; o tutor que adquire bens do tutelado por interposta pessoa.

\footnotetext{
${ }^{1}$ ITURRASPE, Jorge Mosset. Contratos Simulados y Fraudulentos. Tomo I: Contratos Simulados. Buenos Aires: Rubinzal-Culzoni, 2001, p. 59 e 60.

${ }^{2}$ ALBALADEJO, Manuel. Derecho Civil I: Introducción y Parte General. Barcelona: Libreria Bosch, 1970 , p. 508.

${ }^{3}$ JONES, César Coronel. La Simulación de los Actos Jurídicos. Bogotá: Editorial Nomos, 1989, p. 98.
} 


\section{Volume VIII | Número 1 | Ano 2013}

A propósito da causa simulandi, preleciona Nicola Distaso ${ }^{4}$ que, se por um lado a simulação nem sempre é destinada à obtenção de um resultado fraudulento, não se podendo excluir que interesses dignos de uma certa consideração - tais como a necessidade de subtrair-se à solicitações importunas, um escopo de vaidade ou de rèclame, ou o interesse em conservar o crédito para manter certas aparências sociais - possam aconselhar a criação de uma aparência, sem que aqueles que a realizam queiram lesar terceiros, por outro lado, é inegável que o procedimento simulado importa sempre uma mise en scène destinada a enganar alguém, uma fraude nas relações privadas. Ocorre que o engano que emana do procedimento de criação da aparência não é tal, necessariamente, em relação à intenção a que os simulantes se propõem a obter através da sua realização. Sob este aspecto, é sempre exato o ensinamento da doutrina tradicional segundo a qual a intenção dos simulantes pode ser lícita ou fraudulenta, não se podendo excluir que as partes, não perseguindo uma finalidade ilícita, apenas produzam no mundo externo uma falsa aparência, a qual é uma constante própria do procedimento. Em suma, uma coisa é o engano que emana da ilusão, da mise en scène, da não realidade contida na forma imitada, da alteração da realidade; outra é o engano agravado pela intenção de fraudar terceiros ou de violar a lei, não essencial à descrição do fenômeno, mas quase sempre presente, ou melhor, apenas excepcionalmente ausente dos dados do próprio fenômeno.

\subsection{A disciplina do Código Civil Brasileiro de 2002: causa da simulação e sanção de nulidade}

Na disciplina do Código Civil de 1916, para que a simulação fosse considerada defeito do ato jurídico, exigia-se a intenção dos simulantes de prejudicar terceiros ou de violar disposição de lei (art. $103^{5}$ ). O ordenamento, portanto, reprovava tão somente os atos simulados com fins ilícitos.

A disciplina do instituto no Código Civil de 2002, entretanto, suprimiu o dispositivo contendo tal exigência, de modo que surge a indagação: para que a simulação seja considerada defeito é necessário que tenha sido praticada com intuito de prejudicar terceiros ou de violar

\footnotetext{
${ }^{4}$ DISTASO, Nicola. La simulazione dei Negozi Giuridici. Torino: UTET, 1960, p. 79 a 81.

${ }^{5}$ O disposto no art. 103 do Código Civil de 1916 foi legado de Augusto Teixeira de Freitas, o qual havia previsto regra similar (Esboço, art. 523). Não constava no Projeto primitivo apresentado por Clóvis Beviláqua. Deveu-se à Comissão Revisora do Governo a inserção do dispositivo na seção dedicada à simulação.
} 
disposição legal? Qualquer simulação deve ser reprovada pelo Direito? A discussão acerca de tal questão não é nova.

Clóvis Beviláqua, ao comentar o art. 103 do Código Civil de 1916, afirmou “6onsiderar perigosa, apesar de tradicional, a doutrina de que a simulação, que não prejudica terceiros nem frauda a lei, é innocente, e como tal permitida.". Na opinião do citado jurista “melhor seria condemnar a simulação em todos os casos.”

Na mesma esteira de pensamento, Jean Carbonnier, renomado jurista francês, também no séc. XX, após estabelecer a diferença de tratamento no Código Civil francês, entre o regime geral (e liberal) $^{7}$ e o regime excepcional ${ }^{8}$, mais severo, da simulação, asseverou:

L'idée que le droit doit être indifférent à la simulation sous pretexte qu'il y a des simulations licites est contestable à la lumière des faits. Dans l'immense majorité des cas, la simulation sert à une fraude (au préjudice des créanciers, des héritiers, du fisc). Il ne serait peut-être pas d'un moralisme excessif d'ériger en principe l'interdiction de la simulation et, par une généralisation du système de l'a. 1099, al. 2, la nulitté aussi bien de la contre-lettre que de l'acte apparent. Sans se faire trop d'illusions, on peut penser que l'insécurité juridique qui en résulterait aurait un effet préventif. Au demeurant, le probléme n'est pas de savoir si l'on pourra jamais empêcher, en fait, la simulation, mais si le droit doit la reconnaître.

...

On pourrait se demander, cependant, si la simulation, historiquement très proche de la fraude à la loi, ne serait pas mieux à sa place à côté des atteintes à l'ordre public (cf. le plan d'AUBRY et RAU, I, § 34-35). Ce renversement de présentation, il est vrai, supposerait un renversement de conception, et que l'on cessât de faire de la simulation licite le principe, de l’illicite l'exception.

Na Parte Geral, Livro III (Dos Fatos Jurídicos), Título I (Do Negócio Jurídico), Capítulo V (Da Invalidade do Negócio Jurídico), do Código Civil de 2002 vem disciplinada a simulação, apresentando relevantes alterações em relação ao Código anterior:

Art. 167. É nulo o negócio jurídico simulado, mas subsistirá o que se dissimulou, se válido for na substância e na forma.

$\S 1^{\circ}$ Haverá simulação nos negócios jurídicos quando:

I - aparentarem conferir ou transmitir direitos a pessoas diversas daquelas às quais realmente se conferem, ou transmitem;

\footnotetext{
${ }^{6}$ BEVILÁQUA, Clóvis. Código Civil dos Estados Unidos do Brasil Comentado. Quaderni del Master in Sistema Giuridico Romanistico e Unificazione del Diritto: con particolare attenzione all'unificazione del diritto dei contratti in Europa e in America Latina, collana diretta da Sandro Schipani, vol. III/3, Roma: 2005, p. 168.

${ }^{7} \mathrm{O}$ regime geral funda-se em duas proposições: quando a simulação é indiferente ou quando a contra declaração coexiste com o ato aparente. É indiferente a simulação se não produz consequências próprias; é neutra, não prejudica terceiros nem gera proveito às partes contratantes. A coexistência da contre-lettre e do ato aparente, opera-se, segundo o art. 1.321, em duas diferentes esferas de aplicação: uma no que concerne aos efeitos da contra declaração entre as partes (eficácia), a outra no que diz respeito aos efeitos da contre-lettre em relação a terceiros (ineficácia).

${ }^{8} \mathrm{O}$ regime excepcional da simulação é mais rígido, estabelecendo a nulidade, seja somente da contra declaração, seja da contra declaração e do ato aparente.
} 
II - contiverem declaração, confissão, condição ou cláusula não verdadeira;

III - os instrumentos particulares forem antedatados, ou pós-datados.

$\S 2^{o}$ Ressalvam-se os direitos de terceiros de boa-fé em face dos contraentes do negócio jurídico simulado.

Art. 168. As nulidades dos artigos antecedentes podem ser alegadas por qualquer interessado, ou pelo Ministério Público, quando lhe couber intervir.

Parágrafo único. As nulidades devem ser pronunciadas pelo juiz, quando conhecer do negócio jurídico ou dos seus efeitos e as encontrar provadas, não lhe sendo permitido supri-las, ainda que a requerimento das partes.

Art. 169. O negócio jurídico nulo não é suscetível de confirmação, nem convalesce pelo decurso do tempo.

Atualmente, no Direito Brasileiro, a simulação é causa de nulidade do negócio, consoante disposição expressa contida no caput do art. 167 que, aliás, conservou no parágrafo primeiro e seus incisos, o art. 102 e incisos do antigo Código.

Aplicada, então, a disciplina das nulidades, não mais subsiste vedação à alegação da simulação pelas partes entre si, como determinava o art. 104 do Código de 1916. Esta é a leitura autorizada pela combinação dos artigos 167, caput, e 168, os quais - em perfeita sintonia com o regime das nulidades do respectivo ordenamento - aludem a “qualquer interessado", sem excluir os contratantes ${ }^{9}$.

Este é, dentro do tema da simulação, um dos pontos que mais poderia gerar polêmicas, não fosse a clareza da disposição legal.

A doutrina sustenta a aplicação indistinta dos dispositivos acima citados, abrindo as portas para que a simulação, lícita ou ilícita, possa ser alegada entre as partes simulantes em litígio de um contra o outro.

O enunciado $294^{10}$, aprovado na IV Jornada de Direito Civil do Conselho da Justiça Federal, comprova a assertiva: "Sendo a simulação uma causa de nulidade do negócio jurídico, pode ser alegada por uma das partes contra a outra.”

Embora ninguém negue o alcance das disposições legais sob comento, não estão elas isentas de críticas, como a que tece Marcos Bernardes de Mello ${ }^{11}$ :

\footnotetext{
${ }^{9}$ Nesta mesma senda: MATTIETTO, Leonardo. Negócio Jurídico Simulado (Notas ao art. 167 do Código Civil). Revista Jurídica, v. 349, ano 54, novembro de 2006, p. 104; e PINHEIRO, Maria de Lourdes I. A Simulação no Código Civil de 2002. Direito \& Justiça - Revista da Faculdade de Direito da PUCRS, v. 26, ano 24, agostodezembro de 2002, p. 133.

${ }^{10}$ Disponível em <http://www.apriori.com.br/cgi/for/post10921.html>. Acesso em outubro de 2007.

${ }^{11}$ MELLO, Marcos Bernardes de. Teoria do fato jurídico: plano da validade. 7. ed. rev. e atual. São Paulo: Saraiva, 2006, p. 137.
} 


\section{Volume VIII | Número 1 | Ano 2013}

Revogado o art. 104 do Código Civil de 1916, desapareceu, em face da regra do art. 168 do Código Civil de 2002, a proibição de os que praticaram a simulação nocente não na poderem alegar em litígio entre si ou com terceiros porque foi desconsiderada a prudente e anciã regra, que nos vem do direito romano de que nemo de improbitate sua consequitur actionem. Por isso qualquer um dos figurantes do negócio simulado pode argüir a simulação, inclusive entre si, salvo contra terceiro de boa-fé, porque este é imune aos efeitos da simulação (Código Civil, art. 167, § 2).

Neste sentido, advertimos para o risco de uma das partes em simulação fraudulenta, após ter obtido o escopo ilícito perseguido através da simulação, intentar ação contra a outra parte simulante pretendendo o retorno da situação jurídica ao status quo ante.

É intuitivo que outorgar uma faculdade tal ao simulador fraudulento, que se vê traído por seu próprio cúmplice simulador, representa atribuir um benefício àquele que pratica ato ilícito, enquanto a função da norma, ao contrário, deveria ser a de desestimular a utilização da simulação na prática de ilícitos, de forma a, como assevera Spota ${ }^{12}$ : “mantener la inseguridad jurídica, em torno de los inmorales, con un fin preventivo, sea para que la sanción contra el torpe tenga la mayor probabilidad de aplicarse, sea para satisfacer el propósito de orden público que inspira a toda norma."

Para que fique clara a assertiva, basta que se pense na seguinte hipótese: um devedor, desejando furta-se ao pagamento de seus credores, vende simuladamente seus bens a terceiro para aparentar situação de insolvência. Transcorrido o prazo prescricional para exigibilidade dos créditos, o devedor (simulado alienante) pretende o retorno dos bens ao seu patrimônio e manifesta esta intenção ao outro simulante (adquirente fictício), o qual, agindo com deslealdade, nega-se a efetuar voluntariamente a transferência (“devolução”) dos bens. A lei hoje concede ação ao simulado alienante - que se beneficiou da simulação para prejudicar terceiros (credores) - contra o adquirente fictício para reaver os bens que ele mesmo subtraiu do seu patrimônio. Por conseguinte, o devedor que prejudicou seus credores obtém então a realização completa do plano ilícito que teve em mira ao realizar o negócio simulado $^{13}$. Este, por certo, não pode ser o escopo da lei.

Por isso é que, embora não se possa afastar a possibilidade de que alguém se arrependa de levar a cabo um negócio reprovado por lei, é imperioso que tal arrependimento só possa conduzir à conservação da situação pré-existente à torpeza, nunca a completar a manobra enganosa e

\footnotetext{
${ }^{12}$ Apud ITURRASPE, 2001, p. 68.

${ }^{13}$ ITURRASPE, 2001, p.67.
} 
prejudicial $^{14}$.

Ainda a propósito da sanção legal estabelecida ao negócio jurídico simulado, tratando-se de simulação absoluta o negócio é nulo e não produz nenhum efeito, a teor do disposto no art. 167, caput, primeira parte; por outro lado, o mesmo art. 167, caput, segunda parte, estabelece a validade do negócio dissimulado se preenchidos os requisitos de substância e forma. Isto significa que, reconhecida a nulidade do negócio simulado, eventualmente poderá subsistir o dissimulado, implicando convalidação deste negócio, consoante permissivo do art. 170 do mesmo Diploma Legal ${ }^{15}$.

Optou o legislador por omitir a disposição sobre a intenção das partes em violar a lei ou prejudicar terceiros, não distinguindo, portanto, simulação maliciosa e simulação inocente. Tratada a simulação como causa de nulidade, qualquer negócio simulado é destituído de efeitos (salvo a hipótese de convalidação do negócio dissimulado), não importando a causa da simulação ${ }^{16}$.

José Carlos Moreira Alves, membro da Comissão Elaboradora e Revisora do Projeto do Código Civil brasileiro de 2002, manifestando-se quanto ao tema da simulação afirmou ${ }^{17}$ :

Ao disciplinar a simulação, apartou-se o Projeto inteiramente do sistema observado pelo Código vigente. A simulação, seja a relativa, seja a absoluta, acarreta a nulidade do negócio simulado. Se relativa, subsistirá o negócio dissimulado, se válido for na substância e na forma. Não mais se distingue a simulação inocente da fraudulenta; ambas conduzem ao mesmo resultado: nulidade do negócio simulado, e subsistência do dissimulado, se for o caso. Essa, aliás, a conseqüência - segundo a melhor doutrina que resulta do art. 103 do Código em vigor, que não considera defeito a simulação inocente. Enfim, o Projeto, ressalvando os direitos de terceiros de boa-fé em face dos contraentes do negócio jurídico simulado, admite, como decorrência mesma da nulidade, que a simulação possa ser invocada pelos simuladores em litígio de um contra o outro, ao contrário do que reza o art. 104 da Codificação atual. Também para o Código Civil português de 1967 o negócio simulado é nulo, subsistindo o negócio dissimulado se válido for na substância e na forma; a distinção entre simulação inocente ou fraudulenta - que se entrevê no art. $242^{\circ}$, n. 1 , in fine - não produz qualquer efeito prático, pois a conseqüência, em ambos os casos, é a mesma; e, não obstante os simuladores (ainda que a simulação seja fraudulenta) possam argüir entre si a nulidade do negócio simulado, esta argüição não pode ser feita, por quem simulou, contra terceiro de boa-fé, entendida esta como "ignorância da simulação ao tempo em que foram constituídos os respectivos direitos”.

\footnotetext{
${ }^{14}$ Neste sentido: Llambías e Ordaz, apud ITURRASPE, 2001, p. 67.

${ }^{15}$ A implicação da regra contida no art. 167, caput, quanto aos efeitos da simulação entre as partes, será examinada com maior profundidade no item 2.1.

16 “Toda a simulação, inclusive a inocente, é invalidante.” Enunciado 152 aprovado na III Jornada de Direito Civil do Conselho da Justiça Federal. Disponível em <http://daleth.cjf.gov.br/revista/enunciados/IIIJornada.pdf $>$. Acesso em outubro de 2007.

${ }^{17}$ ALVES, José Carlos Moreira. A parte geral do projeto de Código Civil brasileiro (subsídios históricos para o novo Código Civil brasileiro). 2. ed. aum. São Paulo: Saraiva, 2003, p. 118-120.
} 
De relevância capital o comentário do citado jurista, sobretudo quando menciona a impossibilidade de arguição de nulidade do negócio simulado pelos simulantes contra terceiros de boa-fé, referindo-se à previsão do parágrafo segundo do art. $167^{18}$.

\section{EFEITOS DA SIMULAÇÃO}

\subsection{Entre as partes}

A sanção estabelecida pelo Código Civil de 2002 para o negócio jurídico simulado, como já se referiu, é a de nulidade; logo, decretada a invalidade do negócio, opera-se a sua desconstituição.

Quanto à eficácia ex tunc da sentença desconstitutiva do ato nulo, diverge a doutrina.

Pontes de Miranda ${ }^{19}$, afirma que a sentença que decreta a nulidade do ato jurídico não desconstitui a eficácia do ato em si porque o nulo é, em si mesmo, ineficaz:

O anulável produz efeitos. Só os deixa de produzir quando transita em julgado a sentença constitutiva negativa. Então, apagam-se, como se não tivessem sido (eficácia ex tunc), os efeitos anteriores. Não se dá isso com a decretação do nulo: desconstitui-se o ato jurídico; não, a eficácia, porque não se desconstitui o que não se constituiu. Quando se diz que não se pode impugnar negócio jurídico nulo, ou ato jurídico stricto sensu nulo, porque não há eficácia a extinguir-se, ex tunc, está certo: impugnar é lutar contra efeitos. Mas nem toda a alegação contra o inválido é impugnação: não se impugna o nulo, porque se fez do conceito de impugnação conceito de luta contra o ser e os seus efeitos.

De outro lado, Marcos Bernardes de Melo $^{20}$, sustenta a eficácia retroativa da sentença que decreta a nulidade do ato jurídico:

Diferentemente, tem-se que é ex tunc (= desde antes, desde a origem) a eficácia quando atua em relação ao passado, alcançando efeitos que o ato jurídico a que se refere haja irradiado, eliminando-os, excluindo-os do mundo jurídico, ou criando novos, retroativamente. Na eficácia ex tunc há sempre retroeficácia.

Dessa espécie são exemplos:

(i) As sentenças desconstitutivas (= constitutivas negativas, na terminologia de Pontes de Miranda), porque desconstituem o ato jurídico e os seus efeitos. Nos casos de decretação

\footnotetext{
${ }^{18}$ O parágrafo segundo do art. 167 será objeto de análise específica no item 2.2.

${ }^{19}$ PONTES DE MIRANDA, Francisco Cavalcanti. Tratado de Direito Privado. 4. ed. t. IV. São Paulo: Revista dos Tribunais, 1983, p. 35-36.

${ }^{20}$ MELLO, Marcos Bernardes de. Teoria do fato jurídico: plano da eficácia, $1^{\text {a }}$ parte. $3^{\mathrm{a}}$ ed. rev., São Paulo: Saraiva, 2007, p. 57.
} 
de nulidade e anulabilidade tem-se que a eficácia da desconstituição do ato jurídico é sempre ex tunc: (a) em geral, apenas desjuridicizante, no caso de nulidade, porque não há o que deseficacizar, pois sua eficácia ou (a.a) é apenas aparente, não havendo, portanto, efeitos a desfazer, ou (a.b) excepcionalmente, é putativa, e, nessa hipótese sua ínsita definitividade importa não poder ser desmanchada.

Não obstante a controvérsia em relação aos efeitos da decisão que decreta a invalidade do ato jurídico, a doutrina demonstra um ponto de convergência: a inaptidão do ato nulo de produzir efeitos.

Segundo reza o art. 167, caput, primeira parte, do Código Civil, o negócio simulado é sempre nulo, desprovido de aptidão para a irradiação de efeitos.

Tratando-se de simulação absoluta - aquela que se verifica quando os contraentes, na realidade, não querem celebrar negócio jurídico algum, e só aparentemente o realizam, como, $v$. g., em uma venda simulada feita pelo devedor de um bem de sua propriedade em prejuízo dos credores - a consequência será a desconstituição do negócio jurídico, tão somente.

Porém, descortinado o véu da aparência enganosa (desconstituído o negócio jurídico simulado, nulo), pode ocorrer que as partes tenham, na realidade, celebrado negócio jurídico diverso daquele que fizeram aparentar, colocando em prática o que se denomina simulação relativa $^{21}$. Neste caso, a aplicação do mesmo art. 167, caput, segunda parte, permite a validade do negócio dissimulado se preenchidos os requisitos de substância e forma ${ }^{22}$. Assim, decretada a nulidade do negócio simulado, eventualmente poderá valer o negócio dissimulado, aquele que as partes realmente quiseram celebrar, se preenchidos os requisitos legais substanciais e formais. É o fenômeno que Pontes de Miranda denomina extraversão ${ }^{23}$.

Marcos Bernandes de Mello $^{24}$, no entanto, chama a atenção para o caso de ser maliciosa a simulação: verificada a ilicitude, a nulidade do ato simulado estende-se ao ato dissimulado, sendo

\footnotetext{
${ }^{21}$ Simulação relativa é aquela em que se quer celebrar um determinado negócio jurídico, mas, aparentemente, se realiza outro diverso: seja quanto ao caráter (venda por preço vil quando se quer na verdade realizar uma doação), aos sujeitos (venda feita a terceira pessoa para que esta aliene a coisa à esposa do primeiro vendedor), ou ao conteúdo (objeto do ato ou contrato diverso do real); cláusulas não sinceras, por exemplo, o preço na compra e venda superior ou inferior ao efetivamente pactuado; e uso de datas falsas ou lugar da celebração do ato não correspondente à realidade. Nesta espécie de simulação realizam-se dois atos jurídicos: de um lado o ato ostensivo, simulado, aparente, de outro, o ato oculto, real, dissimulado, que é o verdadeiro.

22 "Na simulação relativa, o aproveitamento do negócio jurídico dissimulado não decorre tão somente do afastamento do negócio jurídico dissimulado, mas do necessário preenchimento de todos os requisitos substanciais $e$ formais de validade daquele." Enunciado 293 da IV Jornada de Direito Civil do Conselho da Justiça Federal. Disponível em «http://www.apriori.com.br/cgi/for/post10921.html». Acesso em outubro de 2007.

23 "Exsurgimento do ato dissimulado, como ato jurídico, no lugar do ato jurídico simulado." PONTES DE MIRANDA, 1983, p. 402.

${ }^{24}$ MELLO, 2006, p. 132.
} 
incabível a extraversão. Esta a razão pela qual não se pode desprezar a relevância da distinção entre simulação lícita e ilícita, verbis:

Quando há simulação nocente, o ato simulado é, em essência, um ato ilícito, de modo que a nulidade deve alcançar não apenas o ato simulado como também o dissimulado, que houver, sendo inadmissível a extraversão. Só no que respeita a terceiros de boa-fé será possível haver eficácia jurídica, mesmo havendo nocência (art. 167, § $2^{\circ}$ ). Em caso de inocência, porém, não só prevalecem os efeitos relativos a terceiros de boa-fé, como se poderá dar efetividade ao negócio jurídico dissimulado que houver, por meio da extraversão.

Como se vê, não há como desconsiderar-se a distinção entre simulação nocente e inocente.

Tal orientação merece alguns esclarecimentos. Desde os Glosadores ${ }^{25}$ a essência da simulação é representada pela expressão aliud agere, aliud simulare, significando a antítese, a contraposição, entre o comportamento de fato (realidade negocial) e o ato negocial (simulado), sancionada com a prevalência da rei veritas sobre a aparência simulada. Disto, porém, não resulta automaticamente a validade do negócio dissimulado; para que isto ocorra, é necessário procederse à verificação da existência ou não de eventuais vedações e impedimentos normativos que se tenham pretendido evitar através do comportamento simulatório.

Em obra sobre o tratamento científico do tema pelos mestres das glosas, Fulvio Mancuso, jurista italiano, discorrendo sobre a simulação relativa afirma que ${ }^{26}$ :

Também destituída de incertezas é a idéia da simulatio de contractu ad contractum: usando uma linguagem menos técnica (simulatio de causa ad causam) mas certamente mais direta, Azo esclareceu que se tem a simulação relativa em sentido próprio e pleno uma vez que o simulatum e o actum conduzam a duas hipóteses representativas de negócios completamente diversos. As partes representam, simulando, uma compra e venda e na realidade estipulam uma doação. O caso recordado por Azo é de uma doação (vedada) entre cônjuges celebrada por trás de uma aparente compra e venda: à nulidade do simulatum corresponde, em dita hipótese, enquanto ilícita, também a nulidade do negócio realmente estipulado (doação). Diversamente, no caso de não ser impedida aos sujeitos a estipulação do negócio dissimulado, a nulidade da compra e venda simulada

\footnotetext{
${ }^{25}$ Para maiores informações acerca da simulação no período das glosas ver MANCUSO, Fulvio. La Teorica della Simulazione nell'Esperienza dei Glossatori: Da Irnerio ad Accursio e da Graziano a Giovanni Teutonico. Bologna: Monduzzi, 2004.

${ }^{26}$ MANCUSO, 2004, p. 129. Tradução livre de: “Altrettanto priva di incertezze è l'idea della simulatio de contractu ad contractum; usando un linguaggio meno tecnico (simulatio de causa ad causam) ma certamente più diretto, Azzone chiarì che la simulazione relativa in senso proprio e pieno si ha allorchè il simulatum e l'actum siano riconducibili a due ipotesi rappresentative di negozi affatto diversi. Le parti rappresentano, simulando, una compravendita e in realtà stipulano una donazione. Il caso rammentato da Azzone è quello di una donazione (vietata) tra coniugi celata dietro una apparente compravendita: alla nullità del simulatum corrisponde, in detta ipotesi, in quanto illecita, anche la nullità del negozio in realtà stipulato. Diversamente, qualora ai soggetti non sia impedita la stipula del negozio dissimulato, alla nullità della simulata compravendita si contrappone la validità e dunque il pieno dispiegamento degli effetti della donazione.”
} 


\section{Volume VIII | Número 1 | Ano 2013}

contrapõe-se à validade, e, pois, ao pleno desdobramento dos efeitos da doação.

Prossegue Mancuso ${ }^{27}$, analisando glosa de Acúrsio: “No caso da doação entre cônjuges, a simulação é instrumento de realização de um negócio ilícito. Por este motivo, nulo é o ‘simulatum' (a aparente venda) mas nulo é, também, o ‘actum' (a doação).”

Se o negócio jurídico simulado consiste em uma compra e venda, e este negócio foi celebrado com a finalidade de ocultar uma doação que a lei considere anulável (como por exemplo, a hipótese prevista no art. 550 do Código Civil ${ }^{28}$ ), esta doação permanecerá anulável, porque a invalidade em menor grau é ex lege. O mesmo ocorreria se o negócio dissimulado fosse, por força de lei, considerado nulo.

Neste sentido valemo-nos também dos ensinamentos de Pontes de Miranda ${ }^{29}$, muito úteis, ainda que professados sob a égide do Código anterior:

A extraversão ocorre ainda que o ato jurídico aparente, se entrasse no mundo jurídico, tivesse de ser tido por nulo, ou anulável; porque só se hão de exigir existência e validade ao ato jurídico dissimulado.

Se o ato jurídico aparente foi por simulação relativa nocente, entrou no mundo jurídico o suporte fático. O ato jurídico é apenas anulável. Enquanto não se decreta a anulação, ele é, e pode ser que prescreva a ação de anulação: não há pensar-se em substituição dele pelo ato jurídico dissimulado. Após a decretação, nada fica do acordo reprovável de vontades. Nem havia, nem há qualquer possibilidade de extraversão.

O primeiro pressuposto para que o ato jurídico dissimulado se extraverta é que tenha havido o elemento volitivo suficiente para ele. O princípio de que a vontade precisa ser manifestada também aqui cabe, posto que possa ser tácita. Depois vêm os outros pressupostos.

Se a simulação é relativa e inocente, única espécie em que os figurantes podem alegar simulação relativa, então, sim, a sentença estabelece o que realmente foi querido pelos figurantes em lugar do que foi simulado.

Logo, para que o negócio jurídico dissimulado seja válido entre as partes, além de estar conforme ao ordenamento jurídico no que tange aos requisitos de substância e forma, é necessário que não tenha sido celebrado com intuito ilícito, ou seja, deve ser negócio jurídico oculto em simulação inocente.

Este também o posicionamento da doutrina nacional contemporânea, apresentado na III

\footnotetext{
${ }^{27}$ MANCUSO, 2004, p. 151. Tradução livre de: "Nel caso della donazione fra coniugi, la simulazione è strumento di realizzazione di un negozio illecito. Per questo motivo, nullo è il simulatum (l’apparente vendita) ma nullo è altresì, l'actum (la donazione)."

${ }^{28}$ Art. 550. A doação do cônjuge adúltero ao seu cúmplice pode ser anulada pelo outro cônjuge, ou por seus herdeiros necessários, até 2 (dois) anos depois de dissolvida a sociedade conjugal.

${ }^{29}$ PONTES DE MIRANDA, 1983, p. 402-403.
} 


\title{
Volume VIII | Número 1 | Ano 2013
}

Jornada de Direito Civil do Conselho da Justiça Federal, que culminou na aprovação do Enunciado $153^{30}$, segundo o qual: “Na simulação relativa, o negócio simulado (aparente) é nulo, mas o dissimulado será válido se não ofender a lei nem causar prejuízo a terceiros.”

Portanto, em ambos os casos (simulação absoluta ou relativa), existe um negócio jurídico simulado. Este negócio simulado, aparente, enquanto tal, por si só não produz qualquer efeito inter partes. No caso da simulação relativa, se as partes na realidade quiseram celebrar um negócio diverso do simulado, o dissimulado será válido entre elas, desde que lícito e conforme às disposições legais a ele aplicáveis ${ }^{31}$.

\subsection{Perante terceiros}

O parágrafo segundo do art. 167 prevê a ressalva dos direitos de terceiros de boa-fé em face dos contraentes do negócio jurídico simulado.

Esta é a expressão no Direito Pátrio do princípio da inoponibilidade da simulação aos terceiros de boa-fé ${ }^{32}$, o qual, na dicção de Francesco Ferrara ${ }^{33}$, é

\begin{abstract}
estabelecido a favor de terceiros, não contra eles. Donde se segue que, se os terceiros podem contestar a prova da simulação que lhes seja oposta e torná-la inoperante a seu respeito, tem também a faculdade de se servirem das contradeclarações feitas pelas partes, ou de prova de qualquer forma usem, para restabelecer a inexistência ou ocultação do negócio jurídico, afim de obter conseqüências em vantagem própria. Isto é, podem os terceiros renunciar aos benefícios da lei, pela qual em relação a eles é decisivo o contrato aparente, cujos efeitos não podem ser destruídos pela prova que os contratantes aduzem duma intenção contrária e deliberada.
\end{abstract}

Note-se que se trata de uma exceção à regra da nulidade do negócio simulado prevista no caput do mesmo art. 167. Por conseguinte tem-se que um negócio jurídico nulo, por expressa determinação legal, possa produzir seus efeitos em relação aos terceiros de boa-fé "em face dos contraentes do negócio jurídico simulado”.

Tal perspectiva pode, prima facie, parecer equivocada à luz da teoria das nulidades, já que o nulo não produz efeitos, não passa do plano da validade para o plano da eficácia.

\footnotetext{
${ }^{30}$ Disponível em «http://daleth.cjf.gov.br/revista/enunciados/IIIJornada.pdf». Acesso em outubro de 2007.

${ }^{31}$ PETTI, Giovanni Battista. Commentario teorico-pratico al Codice Civile diretto da Vittorio de Martino: Libro IV - Delle obbligazioni: La simulazione e l'invalidità del contratto, art. 1414-1469. Novara: Edipen, 1984, p. 39 e 40.

32 Exemplos no Direito Comparado: Código Civil Italiano, art. 1415; Código Civil Austríaco, § 916 (2); Código Suíço das Obrigações, art. 16; Código Civil Paraguaio, arts. 308 e 309.

${ }^{33}$ FERRARA, Francesco. A Simulação dos Negócios Jurídicos. Tradução de A. Bossa. São Paulo: Saraiva, 1939, p. 360.
} 


\section{Volume VIII | Número 1 | Ano 2013}

Contudo, se atentarmos para a circunstância de que excepcionalmente o nulo também pode produzir efeitos, veremos que a técnica do legislador do Código não abandonou o rigor científico para privilegiar a boa-fé e a tutela da confiança. Ao contrário, adotou coerente solução, sancionando energicamente com a nulidade o negócio jurídico simulado, este vazio jurídico semeador de incertezas, e, ao mesmo tempo, protegendo aqueles que ficam à mercê da aparência enganosa e que vêm a ser os mais prejudicados: os terceiros de boa-fé.

Discorrendo sobre a possibilidade de o nulo, eventualmente, produzir efeitos, afirma Antônio Junqueira de Azevedo ${ }^{34}$ :

Às vezes, pode ocorrer que, por exceção, um negócio nulo produza efeitos jurídicos (são os chamados efeitos do nulo), embora nem sempre esses efeitos sejam os próprios, ou típicos, como acima definidos.

Todavia, é inegável que os casos de efeitos do nulo são exceções no sistema de nulidades e como tais devem ser tratadas. Os efeitos do nulo não são, em sua maior parte, também como havíamos salientado, os efeitos próprios do ato (isto é, os efeitos manifestados como queridos), e, portanto, nesses casos, não se pode dizer que o negócio tenha passado para o plano da eficácia; todavia, ainda quando se trate de eficácia própria, tal e qual ocorre no casamento putativo e em algumas outras poucas hipóteses, tem-se, se pudermos expressar-nos assim, um "furo" na técnica de eliminação com que os negócios são tratados; é a exceção que confirma a regra, tanto mais que, depois de o negócio haver entrado no plano seguinte, o sistema corrige a falha, impedindo que o negócio continue a produzir efeitos (a entrada dos negócios nulos no plano da eficácia não é, pois, definitiva.

\subsubsection{Terceiros de boa-fé}

A simulação não pode ser arguida pelos contraentes do negócio jurídico simulado contra os terceiros de boa fé.

Na lição de Francesco Ferrara ${ }^{35}$ são terceiros alheios ao negócio jurídico simulado:

aqueles que não figuraram de modo algum no contrato simulado, nem nêle foram representados, nem são sucessores universais das pessoas que intervieram no contrato simulado. É possível, no entanto, que os herdeiros assumam, excepcionalmente a qualidade de terceiros quando se trata de defender um direito próprio que a lei lhes concede, como os herdeiros legitimarios que impugnam qualquer acto do autor da herança que lese o seu direito.

Sob o conceito amplo de terceiros estão pois compreendidos os que derivam o seu direito das partes a título particular, os adquirentes, subadquirentes, concessionários dum direito real, etc. e os credores quirografários.

\footnotetext{
${ }^{34}$ AZEVEDO, Antônio Junqueira de. Negócio jurídico: existência, validade e eficácia. 4. ed. atual. de acordo com o novo Código Civil (Lei nº 10.406, de 10-1-2002), São Paulo: Saraiva, 2002, p. 49 e 64.

${ }^{35}$ FERRARA, 1939, p. 361.
} 


\section{Volume VIII | Número 1 | Ano 2013}

Mas não basta ser terceiro para gozar da proteção legal contida na norma do art. 167, parágrafo segundo; deve haver boa-fé, entendida como ignorância da simulação, consoante lição de Ferrara ${ }^{36}$ : "A segunda condição... é que os terceiros estejam de boa-fé, isto é que ignorem que o negócio em cuja seriedade se fiaram ao contratar ou do qual derivam os seus direitos, seja simulado.”

A doutrina nacional comunga deste entendimento. Alberto Júnior Veloso ${ }^{37}$ professa: "Nunca é demais lembrar que a boa-fé do terceiro consiste em desconhecer a simulação, pois se dela tem conhecimento, não há como escapar da nulidade do negócio aparente, e, portanto, será alcançado pelos seus efeitos.”

Os terceiros de boa-fé contam, portanto, com a tutela expressa e incondicional do parágrafo segundo do art. 167, podendo alegar contra as partes o caráter meramente aparente do negócio jurídico, que, no entanto, perante eles será considerado eficaz.

Por outro lado, se o terceiro tiver conhecimento da simulação, podem as partes oporlhe a simulação, e contra ele produzirá efeitos o negócio oculto ou dissimulado (desde que preencha os requisitos de substância e forma, observadas as disposições legais a ele aplicáveis; caso contrário o negócio é igualmente nulo).

\subsubsection{Conflito entre terceiros de boa-fé}

Os juristas que se ocuparam da simulação advertiram para a possibilidade de ocorrer conflito entre duas diferentes categorias de terceiros de boa-fé.

Em face de um mesmo negócio jurídico simulado pode haver, de um lado, o interesse em que prevaleça a verdade real (e eventualmente, havendo, o negócio oculto, dissimulado), e, de outro, o interesse na validade e eficácia do negócio jurídico simulado.

A orientação da doutrina tende à eficácia do ato aparente. Esta solução seria a mais conforme com o valor inspirador do princípio da inoponibilidade da simulação aos terceiros de boa-fé, qual seja, garantir segurança àqueles que confiam nos atos ostensivos ${ }^{38}$.

Deve-se, no entanto, perquirir acerca da justiça desta solução nos diferentes casos

\footnotetext{
${ }^{36}$ FERRARA, 1939, p. 362.

${ }^{37}$ VELOSO, Alberto Júnior. Simulação - Aspectos Gerais e diferenciados à luz do Código Civil de 2002. Curitiba: Juruá, 2004, p. 168.

${ }^{38}$ ALESSANDRI, Arturo.; SOMARRIVA, Manuel.; VODANOVIC, Antônio. Tratado de Derecho Civil: Partes Preliminar y General. t. II. Santiago: Editorial Jurídica de Chile, 1998, p. 365.
} 


\section{Volume VIII | Número 1 | Ano 2013}

concretos, levando-se em consideração as hipóteses mais comuns de terceiros, vítimas de negócios jurídicos simulados.

Alberto Júnior Veloso ${ }^{39}$, acrescentando colaborações pessoais à proposição de Beleza dos Santos, apresenta uma série de hipóteses de conflito entre terceiros de boa-fé, com diferentes soluções, a saber:

a) conflito entre credores do alienante aparente e do adquirente fictício: prevalece a nulidade do ato aparente, e, assim, a pretensão dos credores do fictício alienante. Sendo caso de simulação absoluta, o negócio jurídico aparente será declarado nulo, e os bens serão considerados como integrantes do patrimônio do alienante aparente;

b) conflito entre credores comuns do simulado alienante e sucessores a título singular por aquisição translativa ou constitutiva - do adquirente fictício: o ato aparente será considerado eficaz. Os credores do simulado alienante poderão, porém, rescindir o negócio aparente, como poderiam fazê-lo através de ação pauliana se fosse verdadeiro o negócio, nos casos autorizados por lei;

c) conflito entre sucessores a título singular do simulado alienante e credores comuns do adquirente fictício: não há justificativa para que os credores do adquirente fictício pretendam a permanência no patrimônio do seu devedor, de bens que são legitimamente exigidos por terceiros que adquiriram sobre eles direitos, e em face dos quais o devedor não poderia contrapor uma aquisição legítima. Trata-se de situação similar àquela em que se encontrariam os credores se o devedor fosse evicto de bens que estavam no seu patrimônio, mas que foram reivindicados por terceiros com direito a eles. Considera-se que tais bens estão indevidamente em poder do devedor, simulado adquirente;

d) conflito entre sucessores a título singular do alienante simulado e sucessores a título singular do adquirente fictício:

d.1.) conflito relativo a bens móveis: a solução independe da data em que se realizaram os negócios jurídicos e deve favorecer o terceiro que está na posse da coisa, porque a propriedade da coisa móvel se transfere com a tradição (art. 1627 do Código Civil);

d.2) conflito relativo a bens imóveis: deve prevalecer a alienação que for registrada em primeiro lugar, em harmonia com o disposto nos art. 1.245 do Código Civil e arts. 172 e seguintes da Lei 6.015 de 31 de dezembro de 1973. Não havendo registro de qualquer das

\footnotetext{
${ }^{39}$ VELOSO, 2002, p. 148 a 150.
} 


\section{Volume VIII | Número 1 | Ano 2013}

aquisições, aplica-se a solução estabelecida em relação às coisas móveis, vale dizer, concede-se o direito ao terceiro que estiver exercendo a posse do imóvel;

e) conflito relativo a títulos de crédito - prevalece a cessão de crédito que for primeiro notificada ao devedor, ou de que primeiro for dado conhecimento ao devedor;

f) conflito entre herdeiros legitimários do simulado alienante e subadquirentes de boa-fé pode ocorrer que os herdeiros de um simulado alienante tenham interesse em ver declarada a nulidade de uma aparente alienação que importe redução das legítimas. Por outro lado, à pretensão dos herdeiros pode contrapor-se o interesse de um ulterior adquirente de boa-fé, a quem o adquirente fictício tenha alienado ditos bens e que sofreria grave prejuízo se lhe fosse oposta a nulidade do negócio simulado. Assim, prevalecem os direitos dos subadquirentes, devendo ser tratada a situação como se os bens tivessem saído do patrimônio do autor da herança pela realização de negócio válido e legítimo.

\subsubsection{A solução do Código Civil italiano de 1942 e as “recomendações” doutrinárias na} Argentina

Em relação aos efeitos da simulação em face dos terceiros de boa-fé e ao conflito entre eles, o Código Civil Italiano de 1942 (Libro IV: Delle Obbligazioni, Capo X), estabeleceu o seguinte regramento:

Art. 1415 Effetti della simulazione rispetto ai terzi

La simulazione (164) non può essere opposta né dalle parti contraenti, né dagli aventi causa o dai creditori del simulato alienante, ai terzi che in buona fede (1147) hanno acquistato diritti dal titolare apparente, salvi gli effetti della trascrizione della domanda di simulazione (2652).

I terzi possono far valere la simulazione in confronto delle parti, quando essa pregiudica i loro diritti $(1372,1417)$.

Art. 1416 Rapporti con i creditori

La simulazione non può essere opposta dai contraenti ai creditori del titolare apparente che in buona fede hanno compiuto atti di esecuzione sui beni che furono oggetto del contratto simulato (2910 e seguenti).

I creditori del simulato alienante possono far valere la simulazione che pregiudica i loro diritti, e, nel conflitto con i creditori chirografari del simulato acquirente, sono preferiti a questi, se il loro credito è anteriore (2704) all'atto simulato.

Nicola Distaso ${ }^{40}$ propõe uma distinção fundamental na análise dos vários casos de conflitos derivantes da simulação: entre terceiros que têm interesse na eficácia do negócio

\footnotetext{
${ }^{40}$ DISTASO, 1960, p. 492.
} 


\section{Volume VIII | Número 1 | Ano 2013}

simulado e na ineficácia do acordo simulatório porque as suas relações jurídicas derivam de vínculo com o adquirente simulado; e entre terceiros que seriam prejudicados se declarada a eficácia do negócio simulado e que, por conseguinte, têm interesse em que prevaleça o acordo simulatório, mediante a oposição total ou parcial de ineficácia do negócio simulado, em virtude do prejuízo decorrente de um ato de disposição levado a efeito pelo simulado alienante.

Esclarece Distaso ${ }^{41}$, para dirimir tais conflitos o Código Civil italiano segue três critérios diversos que se integram: (a) tutela da confiança (art. 1.415, alínea 1; e 1416, alínea 2), segundo a qual a simulação é inoponível a quem tenha, de boa-fé, tratado com o titular aparente considerando-o como titular efetivo; (b) irrelevância da aparência perante todos os interessados, sejam as partes (art. 1414), sejam terceiros (art. 1415, alínea 2; art. 1416, alínea 2, primeira parte), razão pela qual a ação de simulação pode ser intentada por qualquer interessado; (c) anterioridade do título (art. 1416, alínea 2) em função do que, entre vários credores, prefere-se aquele que confiou na situação precedente ao negócio simulado.

Consoante já se salientou, o Código Civil brasileiro em vigor não contempla previsão normativa para os casos de conflitos entre terceiros de boa-fé.

Entendemos que a ausência de normas neste sentido dificulta a atividade jurisdicional, impondo ao magistrado o recurso à doutrina - que se socorre das regras e soluções aplicáveis a outros institutos envolvidos, em cada caso -, nem sempre unânime nas soluções adotadas, apresentando sérios riscos de decisões injustas e em sentidos opostos para casos idênticos. Ressalte-se que tampouco as Jornadas de Direito Civil promovidas pelo Conselho da Justiça Federal ocuparam-se da problemática envolvendo o conflito entre as diferentes categorias de terceiros de boa-fé.

Não pretendemos defender aqui, absolutamente, deva o legislador prever todas as possíveis hipóteses de conflito; posicionamo-nos, todavia, no sentido da utilidade da fixação de critérios substanciais de base para a sua resolução.

O Código Civil italiano, demonstrando maturidade na elaboração das regras sobre o tema da simulação e das questões práticas relevantes que suscita para o intérprete e aplicador do Direito, possui normas alicerçadas em critérios seguros e os mais justos - tanto quanto possível orientados pelos princípios que inspiram todo o ordenamento jurídico e que são especialmente vinculados à matéria, princípios estes que se destinam a prover segurança jurídica.

${ }^{41}$ DISTASO, 1960, p. 492 e 493. 
Na Argentina, cujo Código Civil, a exemplo do brasileiro, não possui regras dirimentes de conflitos entre terceiros de boa-fé - e que muito se assemelha, no pertinente ao tema da simulação, à disciplina do Código Civil brasileiro revogado -, existem "recomendações” doutrinárias para a tutela da confiança, que, não obstante incompletas para o fim de solucionar a problemática aqui aludida, ao menos lança e consolida as diretrizes para a atividade interpretativo-criativa da jurisprudência, consoante noticia Jorge Mosset Iturraspe ${ }^{42}$ :

El tema de la confianza en una declaración es inseparable del de la seguridad jurídica y del respecto a la apariencia. En las X Jornadas de Derecho Civil, celebradas en Corrientes, en 1985, la Comisión $\mathrm{N}^{\circ} 8$ se ocupo de los efectos jurídicos de la apariencia, y produjo las "recomendaciones" siguientes: " $1^{\circ}$ ) la protección de la apariencia constituye un principio de Derecho que se extrae de una interpretación integradora del ordenamiento jurídico, y deriva de la finalidad de cubrir las necesidades del tráfico, la seguridad dinámica y la buena fe. $2^{\circ}$ ) El principio puede ser extendido fuera de los casos establecidos siempre que se den los presupuestos de aplicación. $3^{\circ}$ ) Son requisitos generales de la aplicación de la teoría de la apariencia: a) Una situación de hecho que, por su notoriedad sea objetivamente idónea para llevar a engaño a los terceros acerca del estado real de aquélla; b) frente a terceros, entre otros, que no hayan conocido o podido conocer la verdadera situación, obrando con la diligencia debida. $4^{\circ}$ ) En los actos de adquisición de derecho por terceros, se requiere que hayan sido efectuados a título oneroso, salvo norma expresa que establezca la protección del adquirente a título gratuito. $5^{\circ}$ ) Son efectos de la aplicación de la teoría de la apariencia: a) entre las partes del acto: entre otros, en ciertos casos la invalidez del acto queda saneada por la apariencia; b) frente a terceros: entre otros, produce los siguientes: I. Convalida la adquisición del derecho por el tercero de buena fé y a título oneroso que lo obtiene por un acto válido de quien, a su vez, lo tuvo a consecuencia de un acto inválido o ineficaz del adquirente. II. Legítima el ejercicio de un derecho por quien no es su titular (representación aparente). III. En algunos casos produce la inoponibilidad (por ej., contradocumento privado o público no anotado en la escritura matriz). c) Respecto del titular del derecho la pérdida o limitación de su derecho, lo faculta al ejercicio de las acciones resarcitorias que correspondieren.

Propomos, portanto, a reflexão sobre a conveniência de disponibilizar aos operadores do Direito Brasileiro, instrumentos mais efetivos para a solução de controvérsias que, indubitavelmente, poderão advir da interpretação do art. 167, parágrafo segundo, do Código Civil brasileiro de 2002, em casos envolvendo conflitos entre terceiros de boa-fé.

\section{CONSIDERAÇÕES FINAIS}

Da análise procedida nas páginas precedentes resulta evidente que as alterações

\footnotetext{
${ }^{42}$ ITURRASPE, 2001, p. 23 e 24.
} 


\section{Volume VIII | Número 1 | Ano 2013}

promovidas pelo Código Civil de 2002 na disciplina relativa à simulação dos negócios jurídicos é assaz diversa da que lhe era instituída pelo Código Civil revogado. Hodiernamente qualquer que seja a simulação, não importando o motivo que lhe deu vida - intuito inocente ou malicioso das partes -, é reprovada pelo Direito e sancionada com a nulidade do negócio por meio do qual ela se realizou.

Relevante implicação decorrente da sanção de nulidade do negócio jurídico simulado diz respeito à legitimidade para a sua arguição: as partes, atualmente, estão autorizadas a alegar a simulação em litígio de uma contra a outra. Neste sentido, alertamos para a circunstância de que seria inimaginável houvesse o legislador pretendido beneficiar os simuladores com intuito fraudulento, possibilitando a obtenção completa do resultado ilícito por eles perseguido. Assim, concluímos que o permissivo legal deve ser aplicado com cautelas, em cada caso concreto.

Não menos importante consequência da sanção de nulidade, resultante da previsão do art. 167, caput, primeira parte, é a desconstituição do negócio, independentemente de ser a simulação absoluta (aquela em que o único negócio querido pelas partes é o negócio simulado) ou relativa (em que as partes realizam um negócio simulado para ocultar o verdadeiro negócio jurídico havido entre elas). Tratando-se de simulação relativa, porém, o negócio oculto, dissimulado, poderá prevalecer, se for lícito e observar os requisitos substanciais e formais a ele aplicáveis (art. 167, caput, segunda parte).

Também os efeitos da simulação relativamente aos terceiros de boa-fé revestem-se de acentuado interesse prático. O parágrafo segundo do art. 167 coloca o ordenamento jurídico brasileiro na esteira de outras legislações e da doutrina mais autorizada. Tutelando a boa-fé e a confiança, estabelece a ressalva dos direitos dos terceiros em face dos contraentes do negócio simulado. Trata-se de uma exceção à teoria da nulidade: a produção de efeitos do negócio nulo. Assim, mesmo que os simulantes possam alegar entre si a simulação, não podem fazê-lo em relação aos terceiros de boa-fé.

Ainda quanto a este aspecto, mencionou-se a possibilidade de haver conflito entre diferentes categorias de terceiros de boa-fé, os quais podem ser divididos em dois grandes grupos: um deles integrado por aqueles que têm interesse na prevalência - na eficácia - do negócio jurídico simulado porque adquiriram direitos com base neste; o outro, composto por aqueles que têm interesse na desconstituição do negócio simulado, na prevalência da rei veritas (que eventualmente pode ser a subsistência do negócio dissimulado), na medida em que a eficácia 


\section{Volume VIII | Número 1 | Ano 2013}

do negócio simulado prejudica seus direitos.

O Código Civil brasileiro de 2002 carece de normas e critérios específicos que auxiliem na solução de tal conflito, como o faz o Código Civil italiano de 1942, cujas disposições neste particular foram elaboradas com base nos princípios fundamentalmente envolvidos no tema; tampouco o faz a doutrina, sem que tenha que se socorrer de regras próprias de outros institutos, e, mesmo assim, suscitando controvérsias. Neste contexto, entendemos que normas claras, efetivas e específicas - se não exaustivas, que ao menos estabeleçam diretrizes concretas para a resolução destes conflitos -, além de úteis, mostram-se necessárias.

\section{REFERÊNCIAS BIBLIOGRÁFICAS}

ALBALADEJO, Manuel. Derecho Civil I: Introducción y Parte General. Barcelona: Libreria Bosch, 1970.

ALESSANDRI R. Arturo; SOMARRIVA U. Manuel; VODANOVIC H. Antonio. Tratado de Derecho Civil: Partes Preliminar y General. t. II. Santiago: Editorial Jurídica de Chile, 1998.

ALVES, José Carlos Moreira. A parte geral do projeto de Código Civil brasileiro (subsídios históricos para o novo Código Civil brasileiro). 2. ed. aum. São Paulo: Saraiva, 2003.

AZEVEDO, Antônio Junqueira de. Negócio jurídico: existência, validade e eficácia. 4. ed. atual. de acordo com o novo Código Civil (Lei nº 10.406, de 10-1-2002). São Paulo: Saraiva, 2002.

BEVILÁQUA, Clóvis. Código Civil dos Estados Unidos do Brasil Comentado. Quaderni del Master in Sistema Giuridico Romanistico e Unificazione del Diritto: con particolare attenzione all'unificazione del diritto dei contratti in Europa e in America Latina, collana diretta da Sandro Schipani, vol. III/3, Roma: 2005.

CARBOnNIER, Jean. Droit Civil: Les Biens et les Obligations. Tome II. 2a Édition. Paris: Presses Universitaires de France, 1959.

DISTASO, Nicola. La simulazione dei Negozi Giuridici. Torino: UTET, 1960.

FERRARA, Francesco. A Simulação dos Negócios Jurídicos. Tradução de A. Bossa. São Paulo: Saraiva, 1939.

GAINO, Itamar. A Simulação dos Negócios Jurídicos. 2. ed. São Paulo: Saraiva, 2012.

ITURRASPE, Jorge Mosset. Contratos Simulados y Fraudulentos. Tomo I: Contratos Simulados. Buenos Aires: Rubinzal-Culzoni, 2001. 


\section{Volume VIII | Número 1 | Ano 2013}

JONES, César Coronel. La Simulación de los Actos Jurídicos. Bogotá: Editorial Nomos, 1989.

MANCUSO, Fulvio. La Teorica della Simulazione nell'Esperienza dei Glossatori: Da Irnerio ad Accursio e da Graziano a Giovanni Teutonico. Bologna: Monduzzi, 2004.

MATTIETTO, Leonardo. A simulação no novo Código Civil. Revista Trimestral de Direito Civil, v. 13, ano 4, janeiro-março de 2003, p. 111-125.

. Negócio Jurídico Simulado (Notas ao art. 167 do Código Civil). Revista Jurídica, v. 349, ano 54, novembro de 2006, p. 93-107.

MELLO, Marcos Bernardes de. Teoria do fato jurídico: plano da eficácia, $1^{\text {a }}$ parte. 3. ed. rev. São Paulo: Saraiva, 2007.

2006.

. Teoria do fato jurídico: plano da validade. 7. ed. rev. e atual. São Paulo: Saraiva,

PETTI, Giovanni Battista. Commentario teorico-pratico al Codice Civile diretto da Vittorio de Martino: Libro IV - Delle obbligazioni: La simulazione e l'invalidità del contratto, art. 14141469. Novara: Edipen, 1984.

PINHEIRO, Maria de Lourdes I. A Simulação no Código Civil de 2002. Direito \& Justiça Revista da Faculdade de Direito da PUCRS, v. 26, ano 24, agosto-dezembro de 2002, p. 123-134.

PONTES DE MIRANDA, Francisco Cavalcanti. Tratado de Direito Privado. t. IV, 4. ed. São Paulo: Revista dos Tribunais, 1983.

TÔRRES, Heleno Taveira. Teoria da Simulação de Atos e Negócios Jurídicos. Revista dos Tribunais, v. 849, ano 95, julho de 2006, p. 11-56.

VELOSO, Alberto Júnior. Simulação: aspectos gerais e diferenciados à luz do Código Civil de 2002. Curitiba: Juruá, 2004. 